\title{
CONTINENTAL WIND PATTERNS ASSOCIATED WITH COLORADO ALPINE DUST DEPOSITION: AN APPLICATION OF THE BLM/USFS RAWS NETWORK
}

\author{
Morgan Phillips \\ Colorado Climate Center \\ Colorado State University/Bureau of Land Management \\ Nolan Doesken \\ Colorado Climate Center \\ Colorado State University
}

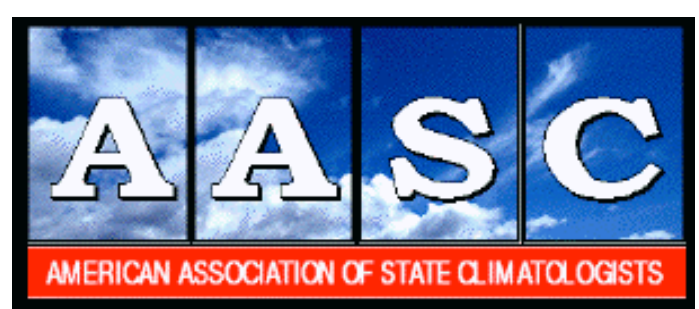

2011

Journal of Service Climatology

Volume 5, Number 2, Pages 1-11

A Refereed Journal of the American Association of State Climatologists 


\title{
Continental Wind Patterns Associated with Colorado Alpine Dust Deposition: An Application of the BLM/USFS RAWS Network ${ }^{1}$
}

\author{
Morgan Phillips \\ Colorado Climate Center \\ Colorado State University/Bureau of Land Management
}

\author{
Nolan Doesken \\ Colorado Climate Center \\ Colorado State University
}

Corresponding Author: Morgan Phillips, Colorado Climate Center, Department of Atmospheric Science, 1371 Campus Delivery, Colorado State University, Fort Collins, CO 80523, USA. Tel. 1-970-491-8312, morganp@,atmos.colostate.edu.com.

\begin{abstract}
The winter and early spring of 2008-2009 brought an unusually high number of alpine dust deposition events to the Rocky Mountains of Colorado. The greatest dust accumulations were observed in the San Juan Mountains of southwestern Colorado. Significant dust accumulation was even observed along the Continental Divide in northern Colorado. The primary source for this dust has previously been identified as the Colorado Plateau. Analysis using the Hybrid Single Particle Lagrangian Integrated Trajectory (HYSPLIT) atmospheric trajectory model along with satellite imagery showed that dust from the 2009 events also originated from the Colorado Plateau, especially from areas in and around northeastern Arizona that were experiencing abnormally dry conditions that spring.

The study utilized data from the BLM/USFS Remote Automated Weather Station (RAWS) network in the southwestern U.S. to identify periods of high winds corresponding to documented Colorado dust events. The RAWS database, once considered to be brief and unsuitable as a climate resource, is quickly approaching 30 years of record and provides a valuable resource for application to various climate questions. Analysis of wind data from these RAWS sites during known dust events show that a minimum threshold wind velocity exists before dust storm generation occurs, and that this threshold velocity occurs from a southwesterly direction. Threshold velocity for the daily mean speed was found to be $15 \mathrm{mph}$ and $44 \mathrm{mph}$ for daily maximum gusts. Wind speeds for the study region were then evaluated for the period January
\end{abstract}

\footnotetext{
${ }^{1}$ A joint research project through the Bureau of Land Management and the Colorado Climate Center
} 
through April for the past 20 years in an attempt to quantify and compare both mean daily wind speed and maximum daily wind gusts on a seasonal basis. A linear regression analysis showed correlation between the Southern Oscillation Index (SOI) and the frequency of these types of high wind periods in the RAWS database, particularly during winter months. This correlation was determined to be 0.46 for daily mean wind speeds and 0.56 for maximum daily wind gusts during the months of December through April. The correlation between periods of high winds and the SOI extends through the 20 years of wind data available for these weather stations.

\section{Introduction}

During the late winter and early spring mid-latitude cyclones and their associated fronts moving through the southwestern United States often generate intense regional dust storms which then move and re-deposit large amounts of airborne sediment in alpine mountain areas (McBride, 2007). Aeolian sediment deposition on alpine snow packs in the western United States is becoming a subject of greater concern as an increasing percentage of the population continues to depend on mountain snow as a source of municipal water supplies (Werner, 2008). The accumulation of dust on mountain snow packs has the potential to alter the snowmelt regime and thus the rate and timing of snowmelt discharge (Painter et al. 2007), as well as having an immediate impact on regional air quality. In addition to water management and air quality issues, the creation of dust sources required for large scale dust storms could also be related to anthropogenic land use activities in arid regions of the southwestern US (Gossens and Buck, 2009).

The primary goal of this study was to define the wind regime associated with the dust events using data from the Remote Automated Weather Stations network (RAWS), while at the same time investigating potential origins of dust found in the San Juan snow pack through a combination of data analysis and atmospheric models. This study also sought to quantify the frequency of high wind periods capable of generating dust storms using the RAWS data set, as previous studies have shown inter-annual variations of wind gust magnitude are related to the El Niño/Southern Oscillation cycle (Enloe, O'Brian and Smith, 2003).

Isotopic analysis has shown that the dust accumulated on the San Juan snow pack during deposition events in 2004/2005 and 2005/2006 seasons originated from the basement rocks and their sedimentary derivatives in the area to the southwest of Colorado known as the Colorado Plateau (Painter et al. 2007). While it is likely that dust from many regions of the globe is transported to, and subsequently deposited in, the San Juan Mountains (Jaffe, Snow and Cooper, 2003), the position of the San Juans relative to the Colorado Plateau suggests that dust sources in the upwind area would be the most likely to contribute to the majority of the aeolian sediment load as the dust laden winds encounter the barrier of high mountain peaks.

The primary source of data used in the study came from the BLM/USFS network of RAWS, which consists of approximately 2,200 automated and manual weather stations that record a variety of atmospheric parameters, including wind speed and direction on a $20 \mathrm{ft}$. mast (BLM/USFS, 2010). Started in the mid 1970 's, the network provides hourly data transmissions via satellite and telemetry to a central database in Boise, Idaho where they are made available to multiple agencies for analysis (Zachariassen et al., 2003). The RAWS network was primarily intended for use in fire weather applications, but due to the rural location of sites in the western US, RAWS data are often the only weather observations available for large areas of land not covered by traditional weather stations (Brown et al., 2001). 


\section{Methodology}

\section{Individual RAWS Analysis}

The project began with a simple visual analysis of hourly wind data from individual RAWS locations in the western US. Stations with periods of sustained high winds ( $>4$ hours) best corresponding to multiple known dust deposition events (Table 1) for several years were then mapped using Geographic Information Systems (GIS) software. The resulting map indicates where conditions were most favorable for the generation of dust storms on a synoptic (non-convective) scale immediately surrounding a recorded deposition event in the San Juan Mountains.

Once several RAWS sites with velocity time series graphs corresponding to dust deposition events had been identified it was possible to determine an average 'threshold' wind velocity above which dust storms were generated. The threshold value was only intended to be a generalization of wind speeds most often observed during a dust storm, since the wind velocity at which the entrainment of soil into the boundary layer begins can vary with different locations and terrestrial conditions (Gossens and Buck, 2009). Since the duration and magnitude of high winds is slightly different for individual dust storms, daily averages were used instead of hourly measurements to obtain a more generalized measurement of wind speed during the period surrounding a known dust event. Determination of threshold values were done for both mean wind speed (hourly 10-minute average wind speed) and maximum wind gusts (maximum 5-second average wind speed per hour), where the average mean daily velocity threshold was found to be $15 \mathrm{mph}$ and the threshold for average maximum daily wind gusts was $44 \mathrm{mph}$. These approximate threshold values associated with known large scale dust storms were then used in the frequency analysis as criteria for high wind velocities.

In addition to analyzing the spatial distribution of stations that corresponded well with dust events, the directional characteristics of the wind were analyzed when wind velocity exceeded the threshold value to determine the dominant wind direction during potential dust generating episodes.

\section{HYSPLIT Trajectory Modeling}

An atmospheric trajectory model from the National Air Resource Laboratory known as the Hybrid Single Particle Lagrangian Integrated Trajectory (HYSPLIT) model was used to further analyze the movement of air parcels during known dust events (ARL). Both back trajectory (for air parcels originating over the

Table 1. Dust Deposition Events for Senator Beck Basin Study Area in the San Juan Mountains from winter of 2002/2003 through winter of 2008/2009 (CDOS, 2009).

\begin{tabular}{|c|c|c|c|c|c|c|c|}
\hline Year & $* 2002 / 2003$ & *2003/2004 & $2004 / 2005$ & $2005 / 2006$ & $2006 / 2007$ & $2007 / 2008$ & $2008 / 2009$ \\
\hline \multirow[t]{5}{*}{ Event Dates } & 3-Feb & 17-Apr & 23-Mar & 23-Dec & 17-Dec & 16-Mar & $11-$ Oct \\
\hline & 22-Feb & 28-Apr & 4-Apr & 15-Feb & 27-Feb & 26-Mar & 13-Dec \\
\hline & 22-Apr & 11-May & 8-Apr & 26-Mar & 27-Mar & 30-Mar & 27-Feb \\
\hline & & & 9-May & 5-Apr & 15-Apr & 15-Apr & 6-Mar \\
\hline & & & & 15-Apr & 18-Apr & 21-Apr & 9-Mar \\
\hline \multicolumn{2}{|c|}{ *Record Incomplete } & & & 17-Apr & 24-Apr & 30-Apr & 22-Mar \\
\hline & & & & 22-May & 4-May & 12-May & 29-Mar \\
\hline & & & & 27-May & 6-Jun & & 3-Apr \\
\hline & & & & & & & 8-Apr \\
\hline & & & & & & & 15-Apr \\
\hline & & & & & & & 24-Apr \\
\hline & & & & & & & 25-Apr \\
\hline
\end{tabular}


deposition area) and forward trajectory (for air parcels originating over the suspected dust source) analyses were carried out for multiple events.

Assuming that entrained dust would travel at roughly the same speed as the boundary layer winds, the approximate time of travel from the suspected source to the San Juan Mountains was determined to be around 8 hours. Since it is unrealistic to assume all events would have the same timing scheme, ensemble runs were made for several events using different initialization and run times. HYSPLIT models were initialized by using weather stations near the suspected source area to determine the approximate time of peak wind velocity. Eta Data Assimilation System (EDAS) $40 \mathrm{~km}$ resolution data sets acquired from the Air Resource Laboratory were used for the analysis. A matrix of 15 origin points centered roughly over the San Juan Mountain range was applied for the back trajectory analysis, while the forward trajectory analysis used a similar matrix of source points centered over the suspected source area in northeastern Arizona. The resolution on both matrices was set at 0.3 degrees.

\section{High Wind Event Frequency}

Analysis of the frequency of high wind days consisted only of the data from January through April, as this is the ideal time for the formation of large scale dust storms in the southwestern US (McBride, 2007). Wind data for the project were acquired from the RAWS network which collects readings of 10-minute average wind speed, direction and 5-second average maximum gust speed from a $20 \mathrm{ft}$. mast every hour (NWCG, 2009). In order to maximize the number of stations included in the analysis the number of years used was limited to 20. RAWS locations with at least 20 years of consistent wind data were then identified throughout the states of Nevada, Utah, Arizona and New Mexico west of $107^{\circ}$ longitude.

Out of the several hundred RAWS sites currently operating over the western U.S., 42 were identified as meeting the required criteria of at least 20 years of record and $90 \%$ complete data. From this initial data set the analysis of high wind event frequency was carried out by counting the number of times the daily mean wind speed and maximum daily wind gusts exceeded the threshold values for each year of record. A 20 year average was created from these data and the values for individual years were then compared against the 20 year average to create an annual departure from average of days with high winds. The annual departures were then compared to the Southern Oscillation Index (SOI). The SOI was chosen for use in this study because of its long period of record and common use in research applications (CPC). SOI data was obtained from the Climate Prediction Center and the index values were averaged over the four month period from January to April and then compared to the wind frequency data for the same time period.

\section{Results and Discussion}

\section{Individual RAWS Analysis}

The results from the visual analysis showed that the majority of RAWS locations with high wind periods best corresponding to known San Juan dust events were located in and around northeastern Arizona. The relationship between periods of sustained high winds and recorded dust events becomes weaker as one chooses stations further and further away from the northeast Arizona area (Figure 1). This pattern suggests that conditions favorable to entraining and transporting aeolian sediment are present mostly in northeastern Arizona during a corresponding dust event in the San Juan Mountains, and therefore the source of this dust is most likely in the target area of northeastern Arizona. These results also suggest that a similar source/sink relationship may be present in other systems, where dust from an area with high sediment availability is commonly deposited on a nearby mountain range.

In addition to the data analysis, visual satellite imagery from Geostationary Operational Environmental Satellite (GOES) and Moderate Resolution Imaging Spectroradiometer (MODIS) instruments also show rising dust plumes during known dust events from the same areas in Arizona where the corresponding weather stations are located. 


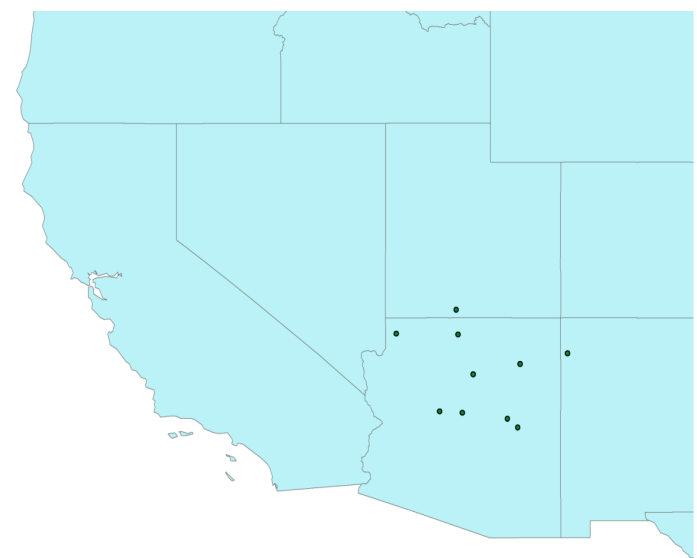

Figure 1. RAWS locations with high wind periods best corresponding to San Juan dust events from 2004 through 2009.

Furthermore, directional analysis of high velocity wind periods at these stations indicates the strongest surface flow is from a southwesterly direction. The directional component of the surface winds appears to be a major indicator as to whether or not a high wind period corresponds to a San Juan dust event. This became evident during the investigation of anomalous high wind periods that did not correspond to dust events in the San Juan Mountains. A good example can be found in the wind analysis of the Hopi, Arizona RAWS location during March 29 through April 3 of 2009 (Figure 2).

Here, a high wind period on April 1 that does not correspond to a dust event in southwest Colorado occurs in-between high wind periods matching dates of known San Juan dust events. Directional characteristics of the high wind period on April 3 (Figure 3) show the strongest surface winds originating from the southwest, while the April 1 high wind event has the highest velocity winds coming from a north/ northwesterly direction (Figure 4). While winds at the surface were strong enough to entrain a large amount of dust during the April 1 event, directional characteristics suggest that the suspended dust was carried south of Colorado by the prevailing north/northwesterly winds associated with that particular storm system

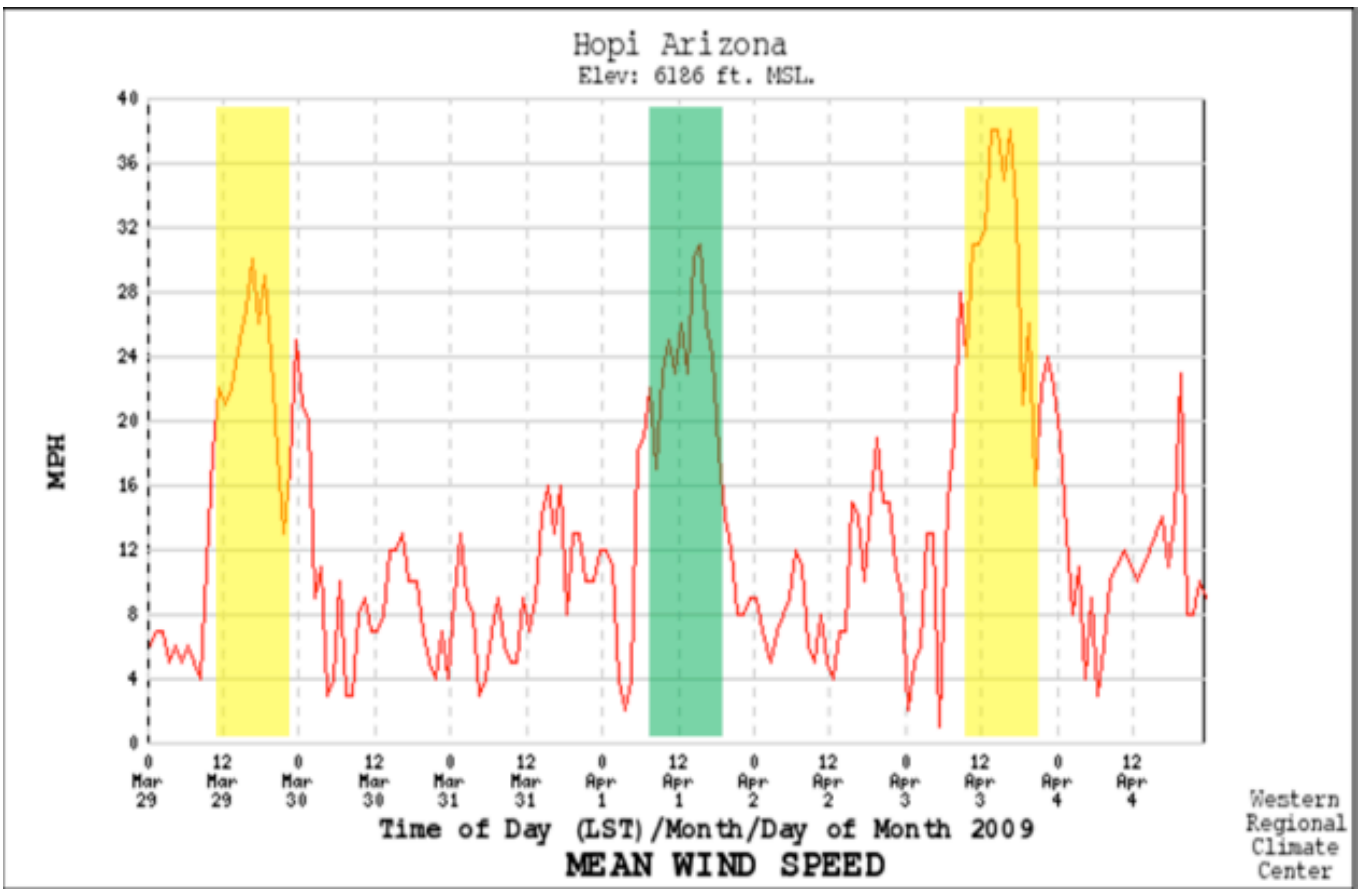

Figure 2. Time series graph of hourly mean wind speed in Hopi, Arizona for March 29, 2009 through April 4, 2009. 


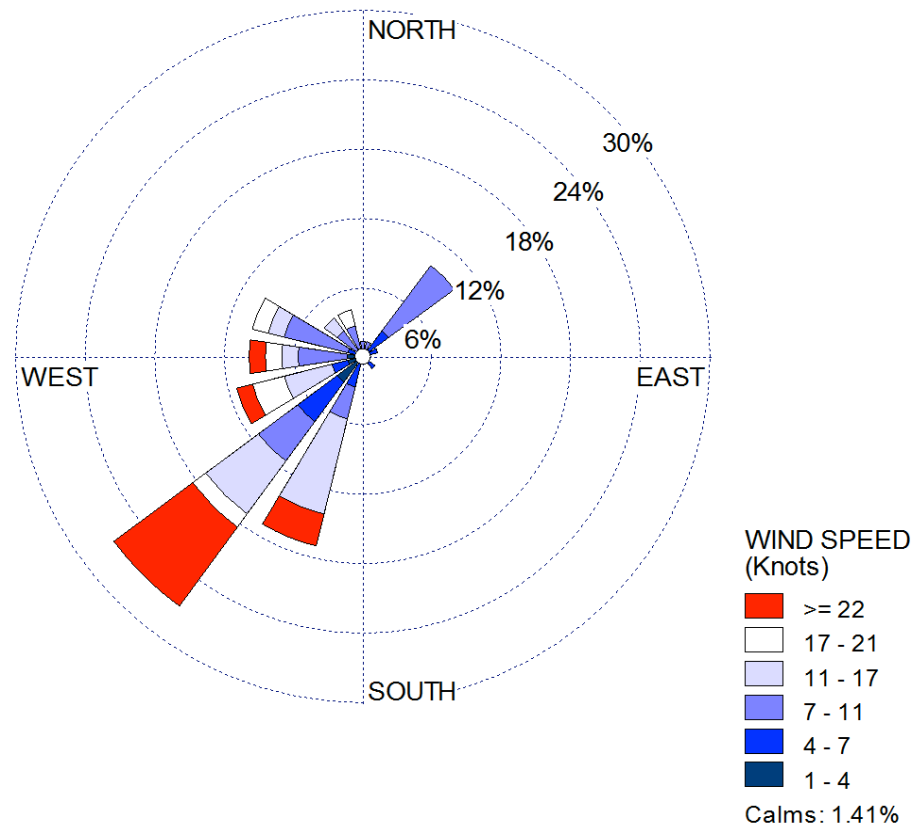

Figure 3. Wind speed distribution for 48 hours surrounding high wind events in Hopi, Arizona which correspond to dust storms in the San Juan Mountains on April 3, 2009.

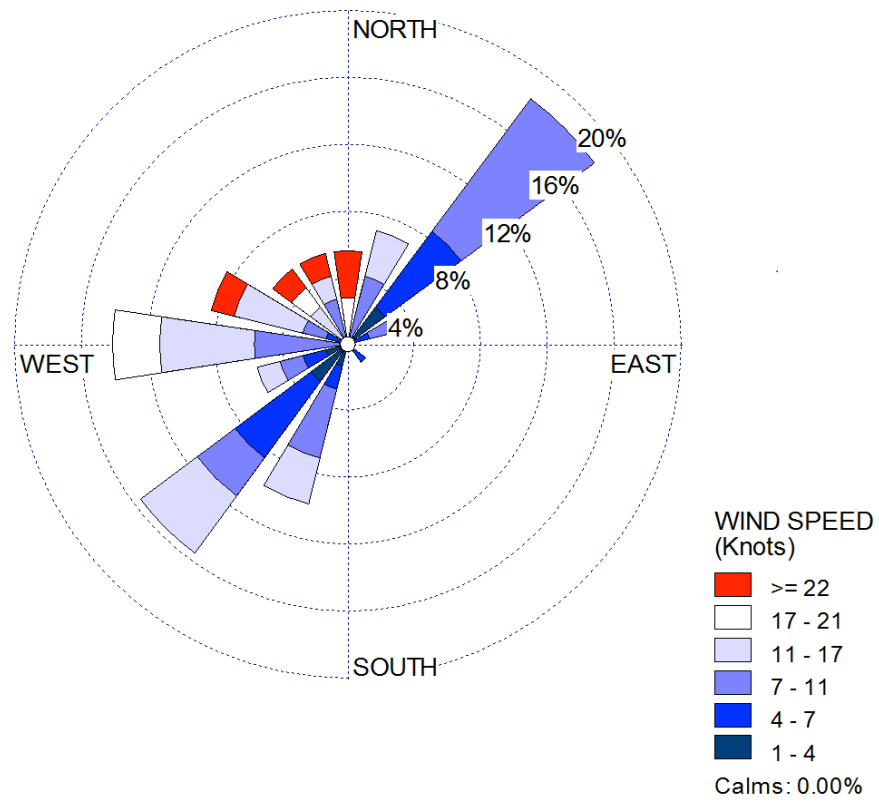

Figure 4. Wind speed distribution for 48 hours surrounding high wind event in Hopi, Arizona not corresponding to a dust storm in the San Juan Mountains on April 1, 2009. 


\section{HYSPLIT Trajectory Modeling}

Using the assumed 8-hour timing scenario, HYSPLIT models show air parcels present over the San Juan Mountains during a dust event originated from northeast Arizona (Figure 5). Similarly, the forward trajectories were initialized during peak wind velocities on days with known San Juan dust events and run for 8 hours resulting in destinations over the southwestern Colorado mountains. Results from ensemble runs using various timing scenarios showed only minor shifts in predicted air parcel trajectories with change in initialization para- meters. Air parcel trajectories tend to move away from the suspected source area as the initialization parameters move away from the 8 hour timing scenario. The resolution for the matrix of source points was decided upon because of both the resolution of the meteorological data and the relatively large scale of the study area. At 0.3 degrees, the matrix is large enough to cover the area of interest while still retaining some level of spatial detail. The use of the model was not meant to isolate specific points of emission, but was intended to show that air parcels over the San Juan Mountains

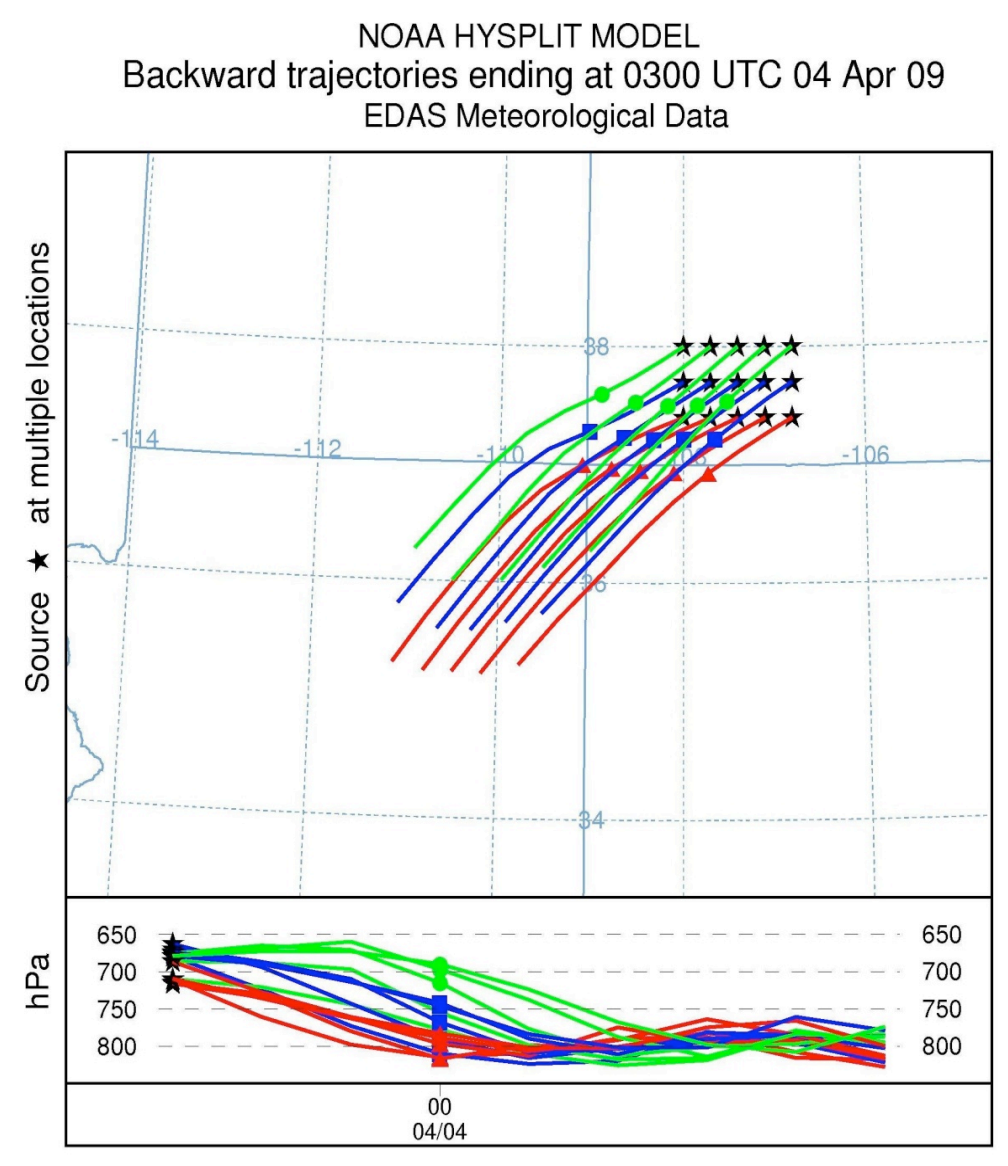

Figure 5. (Above) Back trajectory HYSPLIT model from 19:00 UTC April 3, 2009 to 03:00 UTC April 4, 2009 with air parcel sources indicated with stars. (Below) air parcel pressure (hPa) time series graph with the beginning time of 03:00 UTC April 4, 2009 on the left moving backward in time to 19:00 UTC April 3, 2009 on the right. 
originated from the general area of the suspected dust source in northeast Arizona during known dust events.

\section{High Wind Event Frequency}

The frequency analysis was designed to quantitatively measure the number of high wind events in the southwestern US over a wide spatial range. By combining data from the entire population of 42 stations, a change in the frequency of high wind days could be measured on a broad scale to reveal trends common to all of the stations. Daily summaries were used for mean wind speed instead of hourly values because the investigation was interested in the frequency of discrete, multi-hour periods of high winds rather than isolated periods of high velocity winds not associated with synoptic scale features. By relying only on daily data, the classification of a 'high wind' period should be more representative of an event capable of generating a large scale dust storm.
Using the high wind criteria defined from the individual station analysis, the average number of days on which the mean daily wind speed exceeded $15 \mathrm{mph}$ during January through April was found to be 4.4 days with a standard deviation of 1.1 over the 20 year period, and the average number of days maximum daily wind gusts exceeding $44 \mathrm{mph}$ for the same months was 6.6 days with a standard deviation of 1.6 over the 20 year period.

While the winter of 2009 ranked above the 20 year average in terms of the number of days with high winds, it was not the largest in the period of record (Figure 6). The discrepancy between the unusually high numbers of dust storms in 2009 with only a moderate increase in high wind frequency suggests the involvement of other controlling factors on dust entrainment, such as vegetation cover and antecedent moisture. Indeed, the suspected source area had been experiencing abnormally dry conditions that intensified throughout the winter of 2009 and could have resulted in an increased susceptibility to dust entrainment (Figure 7).

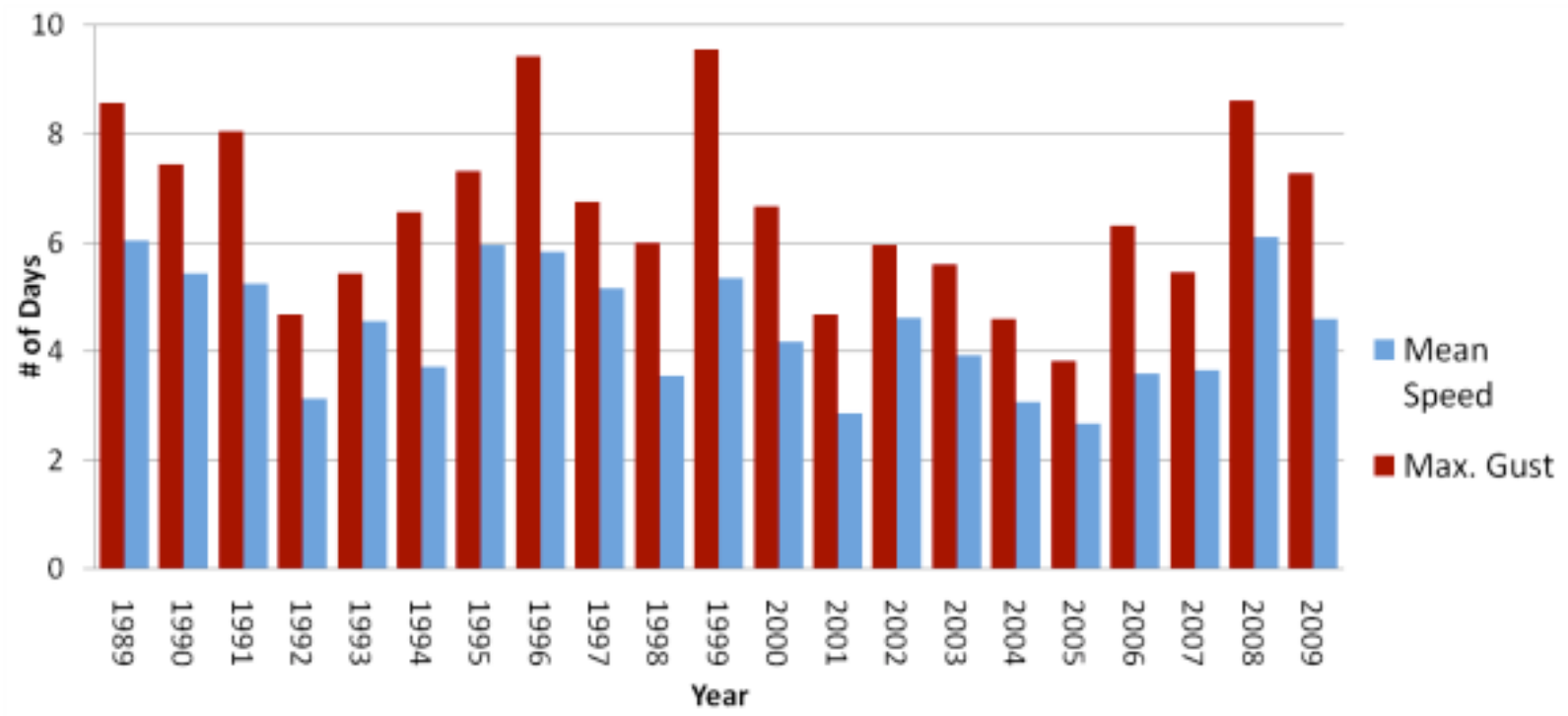

Figure 6. Average number of days (January-April) with mean wind speed $>15 \mathrm{mph}$ and maximum wind gust $>44$ mph for 42 RAWS sites in AZ, NV, UT and western NM. 


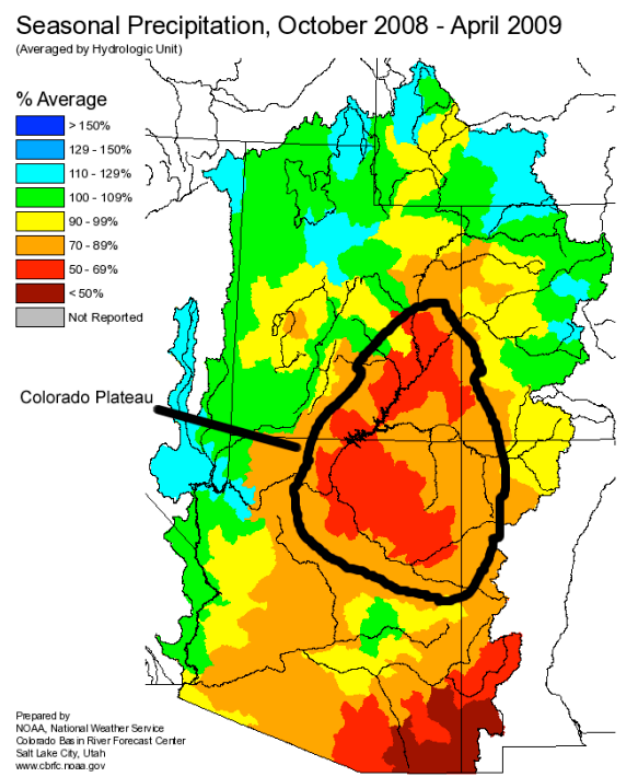

Figure 7. Percent of normal precipitation from October 2008 through April 2009 with the Colorado Plateau indicated (CBRFC, 2009).

Frequency data for the January through April high wind periods were then compared to the Southern Oscillation Index (SOI) values for the same time period. Visual comparison of the time series graphs of departure from average of high wind days to the SOI revealed a corresponding relationship between positive (negative) phases of the SOI to an increase (decrease) in the frequency of high wind periods (Figures 8 and 9).

Linear regression analysis showed a correlation between the mean daily wind speeds and the SOI with a sample correlation coefficient of 0.46. The linear regression of the maximum daily wind gust compared to the SOI for the January through April time period yielded a sample correlation coefficient of 0.56. After evaluating data for the entire year it was discovered that the best correlation between the SOI and high wind frequency occurred in the January through April timeframe, a feature consistent with previous studies (Enloe, O'Brian and Smith, 2000). While these values fall short of proving a statistically significant correlation between the two phenomena, the existence of minor correlation suggests that wind frequency and the SOI are related to each other on some fundamental level throughout the 20 years of data analyzed.

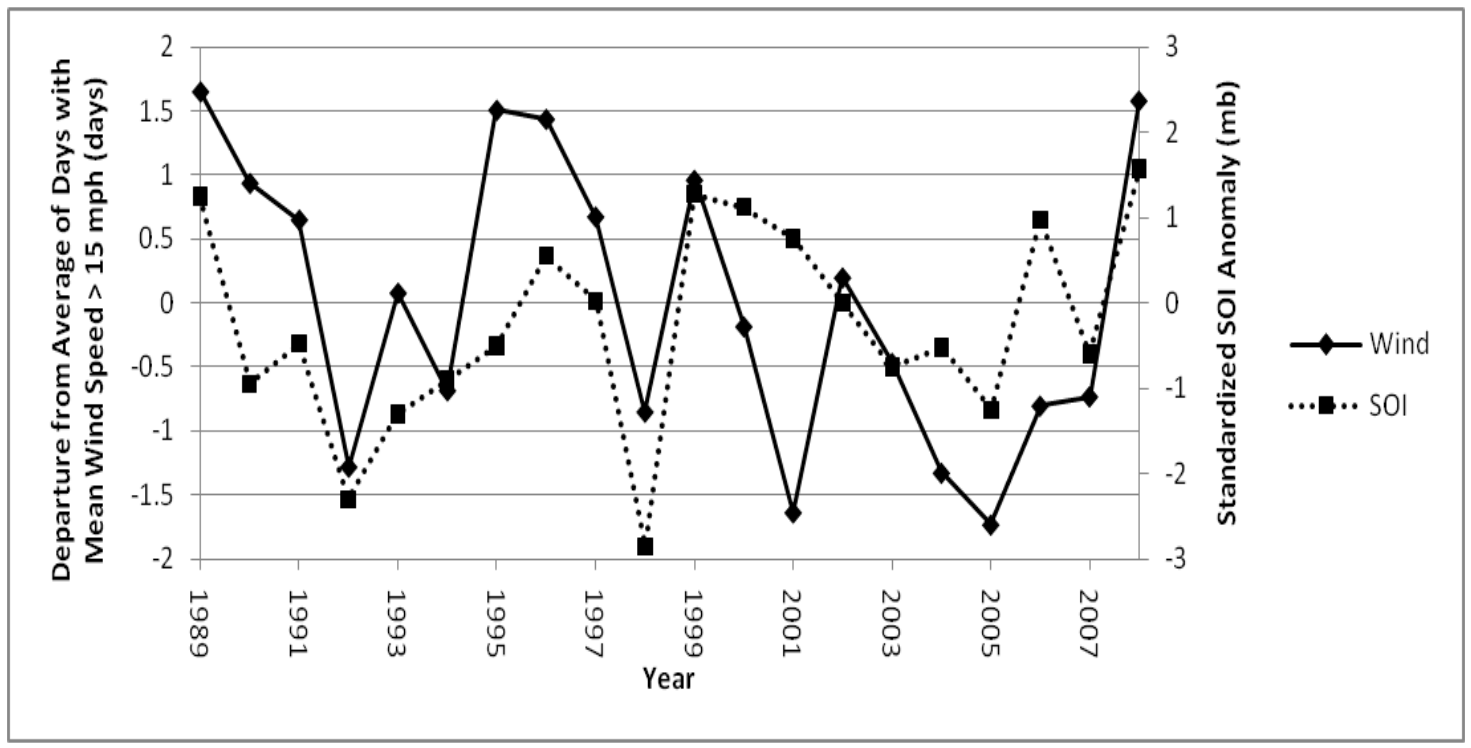

Figure 8. Mean daily wind speed frequency vs. Southern Oscillation Index from January through April for 42 RAWS in AZ, NV, UT and western NM. 


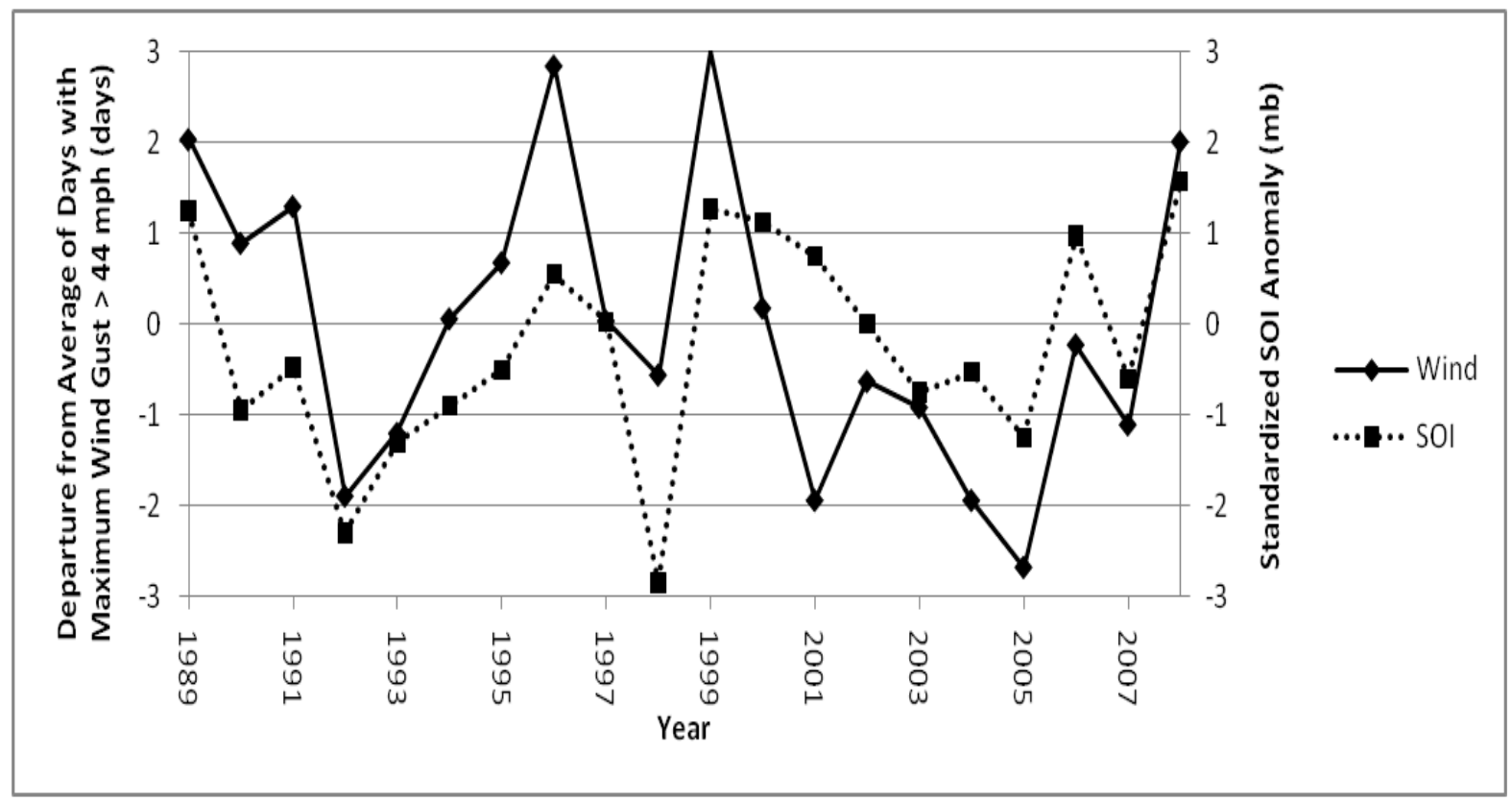

Figure 9. Maximum daily wind gust frequency versus Southern Oscillation Index from January through April for 42 RAWS in AZ, NV, UT and western NM.

\section{Conclusion}

The potential for dust on snow events to impact the already scarce water resources of the western US motivates a better understanding of the mechanisms that cause such events. This study did not seek to comment on the effects caused by non-native dust on the San Juan snowpack, but rather to explore the possible sources of this sediment and the climatological patterns associated with its appearance.

It is worth noting the important role played by the RAWS network throughout the course of this study. The use of the RAWS network as a source of wind data was required simply because of the dearth of wind data available in the rural southwest. In some cases, RAWS sites were the only sources of weather observations for several hundred miles. Additionally, data provided by RAWS sites turned out to be not only reliable, but also temporally extensive. While this study only utilized 20 years of data, many stations are now approaching 30 years of continuous record, and are becoming viable data sources for climatological research applications. This emerging data set will allow for further exploration of large scale dust storms and the relationship they have with the ENSO.

Considering the findings of this investigation, along with the results of other work, this study concludes that most of the dust accumulated on the San Juan Mountains in 2009 originated from the arid basin areas of the Colorado Plateau. The identification of the Colorado Plateau as the primary dust source does not imply that airborne sediment does not come from other sources, but only that the majority of San Juan dust originated from there.

As far as the correlation between increased frequency of high wind periods in the southwestern United States and ENSO, the lack of a significant correlation between the two phenomena illustrates the need for more research before any concrete conclusions can be made. It is clear that some underlying relationship does exist between the ENSO and continental winds; however, the exact magnitude and timing of this effect is as of yet unknown. Aside from the frequency of high winds, it has been shown that ENSO forcing is also related to 
other key factors responsible for the generation of dust storms including vegetation (Lee and Kafatos, 2000) and antecedent moisture conditions. Given the positive results yielded from this study, the connection between ENSO and alpine dust deposition in the San Juan Mountains certainly warrants further investigation as it could conceivable provide regional water managers with a forewarning of increased seasonal dust events.

\section{References}

Air Resources Laboratory (ARL), National Oceanic and Atmospheric Administration, US Department of Commerce.

Brown, T., Hall, B., Redmond, K., and McCurdy, G., 2001. Great Basin RAWS Network Analysis. Program for Climate, Ecosystem and Fire Applications. Desert Research Institute Report 01-01, Reno, NV.

Colorado Basin River Forecast Center (CBRFC), 2009. National Weather Service 2242 W. North Temple, Salt Lake City, UT.

Colorado Dust-on-Snow Program (CDOS), Center for Snow and Avalanche Studies, Silverton, CO.

Climate Prediction Center (CPC), National Oceanic and Atmospheric Administration, Camp Springs, MD 20746.

Remote Automated Weather Stations, Bureau of Land Management and US Forest Service (BLM/USFS), Accessed 12/01/2010.

Enloe, J., O'Brian, J. J., and Smith, S. R., (2003), ENSO Impacts on Peak Wind Gusts in the United States. Journal of Climate. Notes and Correspondence, 17, 1728-1737.
National Wildfire Coordinating Group (NWCG), 2009. Interagency Wildland Fire Weather Station Standards \& Guidlines. PMS 426-3.

Gossens, D., and Buck, B. (2009), Dust emissions by off-road driving: Experiments on 17 arid soiltypes, Nevada, USA. Geomorphology. 107: 118-138.

Jaffe, D., Snow, J., and Cooper, O., (2003), The 2001 Asian Dust Events: Transport and Impact on Surface Aerosol Concentrations in the U.S. Eos, Transactions, American Geophysical Union, 84, No. 46, 501-516.

Li, Z., and Kafatos, M., (2000), Inter-annual Variability of Vegetation in the United States and Its relation to El Niño/Southern Oscillation. Remote Sensing Environ., 71:239-247.

McBride, K., (2007), A Synoptic Climatology for Dust Deposition to the Snowpack in the San Juan Mountains, Colorado, U.S.A. Northern Arizona University: Master's Thesis.

Painter, T. H., A. P. Barrett, C. C. Landry, J. C. Neff, M. P. Cassidy, C. R. Lawrence, K. E. McBride, and G. L. Farmer, (2007), Impact of disturbed desert soils on duration of mountain snow cover, Geophys. Res. Lett., 34, L12502, doi:10.1029/2007GL030284.

Werner, E. (2008, January 31). Study links western water woes to human activities. USA Today. Retrieved from http://www.usatoday.com/weather/environm ent/2008-01-31-nv-water_N.htm.

Zachariassen, J. Zeller, K. Nikolov, N. and McClelland, T. 2003. A Review of the Forest Service Remote Automated Weather Station (RAWS) Network. Rocky Mountain Research Station. US Forest Service. General Technical Report RMRS -GTR119. 